\title{
Abstract
}



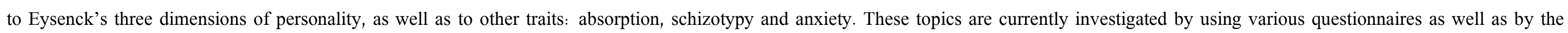

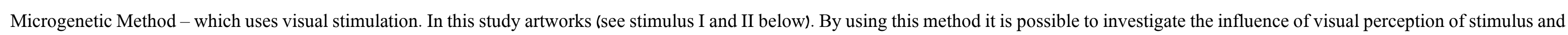


with mental disorders - with or without an aggression background (3) creative-individuals; (4) aggressive-individuals; (5) and a control group.

The expectation was to find relationships between creativity and aggression, especially in psychopathology groups. These relationships connect broadly to the psychoticism dimension of Eysenck's three

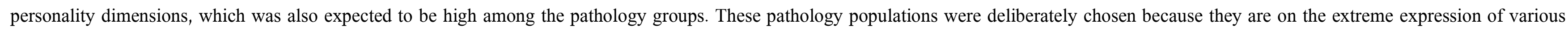

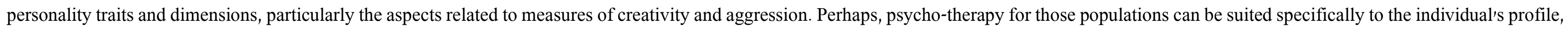
using different creative therapy methods.

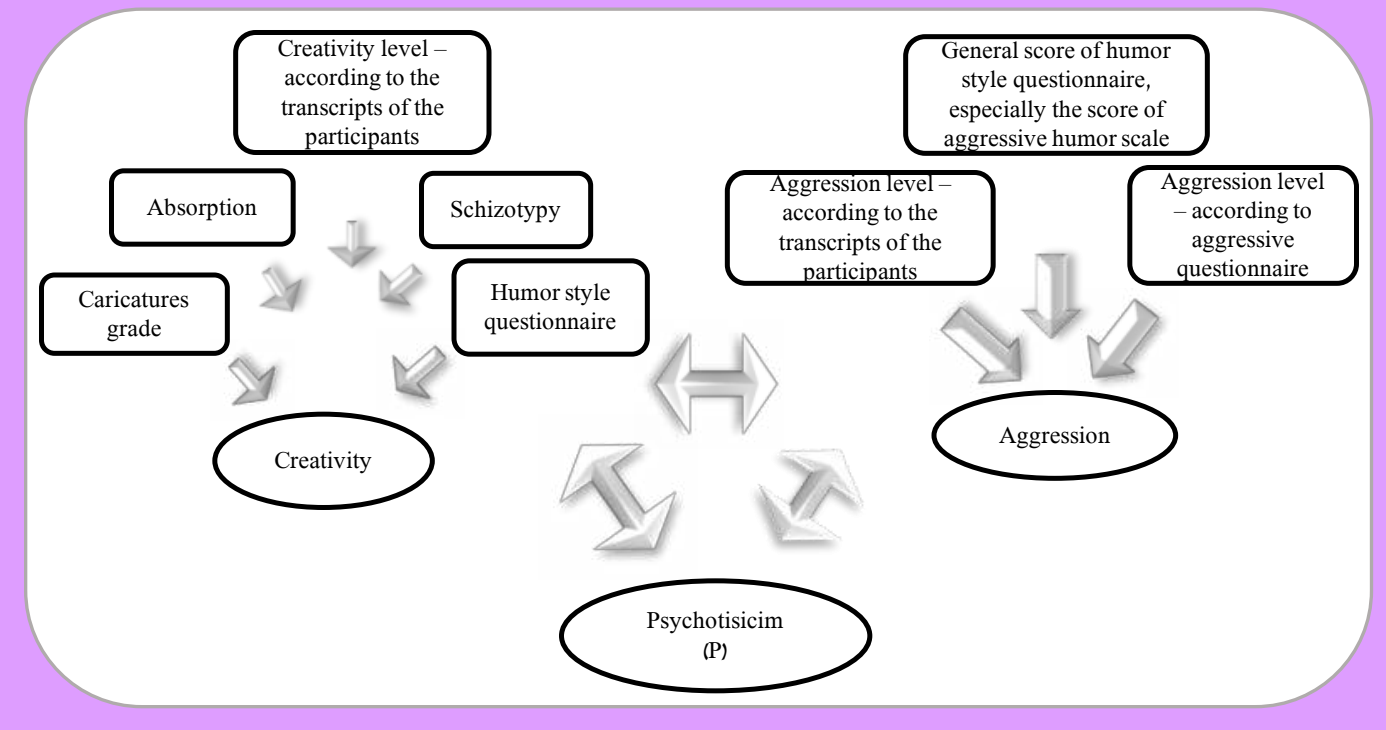

Research assumptions:

A. Stimulus I will stimulate the participants in a different way compare to stimulus II.

B. A correlation will be found between the various variables of creativity and between the various variables of aggression.

C. Creativity and aggression are both attached to Psychoticism (P) dimension. Connection between creativity and aggression will be found and differences between the 5 groups in those traits will be found.

D. Differences in personality profiles of the different research groups will be found, especially based on the personality dimensions of Eysenck:

1) Mental illness - high on $P$ and $N$ scales, and on schizotypy questionnaire. low at $E$.

2) Mental illness (aggressive) - compare to mental illness without an aggressive past behavior: higher on $P$ and $N$ scales and on schizotypy questionnaire.

3) Creatives- high on P and N scales and on schizotypy questionnaire but lower than the mental illness groups. E scale will not be consistent.

4) Aggression- $P$ higher than control group but lower than mental illness, E and $N$ high.

5) Control group - not particularly high or low at any dimension.

E. Gender differences will be found.

\section{First results:}

- Participants had significant different scores in aggression between the stimuli - when "face" aroused higher aggressive reaction and reports that were more diverse.

- The presented results suggest that the group variable do have an effect on the scores of the verbal reports on each category for each stimulate ( 2 scores- total and aggression X 2 stimuli "face" or "murder"). Specifically, our results suggest that creative individuals and aggressive individuals have close mean scores in both the total score and in the aggressive score of both stimuli. Those two groups differ in their scores from individuals coping with mental illness, when the last group has lower scores.

\section{The Microgenetic method results}
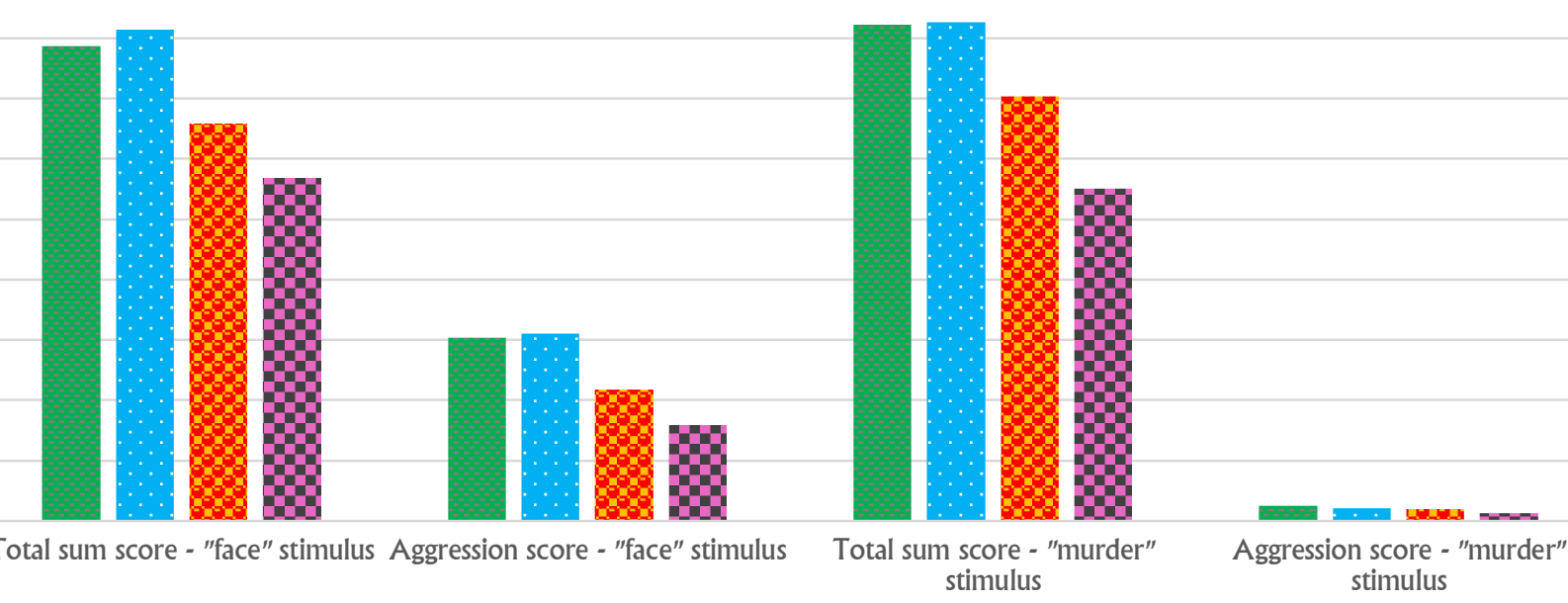

$\underline{\text { Stimulus I (“murder")-“Judith slaying Holofernes” } \backslash \text { Artemisia Gentilescho }}$

\section{(2)} relegreges

Creative woman without a psychiatric past:

\begin{tabular}{|r|l|l|}
\hline & Stimulus I & Stimulus II \\
\hline $1(17 \mathrm{~ms})$ & Puzzle & Frame \\
\hline $2(17 \mathrm{~ms})$ & Light & Lightning \\
\hline $3(33 \mathrm{~ms})$ & Human & Blurring \\
\hline $4(33 \mathrm{~ms})$ & Meeting & Scribble \Scrawl \\
\hline $5(50 \mathrm{~ms})$ & Painting & Become clear $\backslash$ brighten \\
\hline $6(50 \mathrm{~ms})$ & Blurring & Orange \\
\hline $7(67 \mathrm{~ms})$ & Shadow & Opposite colors \\
\hline $8(67 \mathrm{~ms})$ & Filling & Obliquely \\
\hline $9(83 \mathrm{~ms})$ & Close \near & Yellow \\
\hline $10(83 \mathrm{~ms})$ & Photography & Become consolidated $\backslash$ become united \\
\hline $11(117 \mathrm{~ms})$ & Become clear $\backslash$ brighten & Blur \\
\hline $12(117 \mathrm{~ms})$ & Woman & Human being \\
\hline $13(167 \mathrm{~ms})$ & Painting & Shout \\
\hline $14(167 \mathrm{~ms})$ & Publication & \\
\hline
\end{tabular}

$\underline{\text { Stimulus II ("face") - "Potrait of the poet Kleist"\ Andre Masson }}$

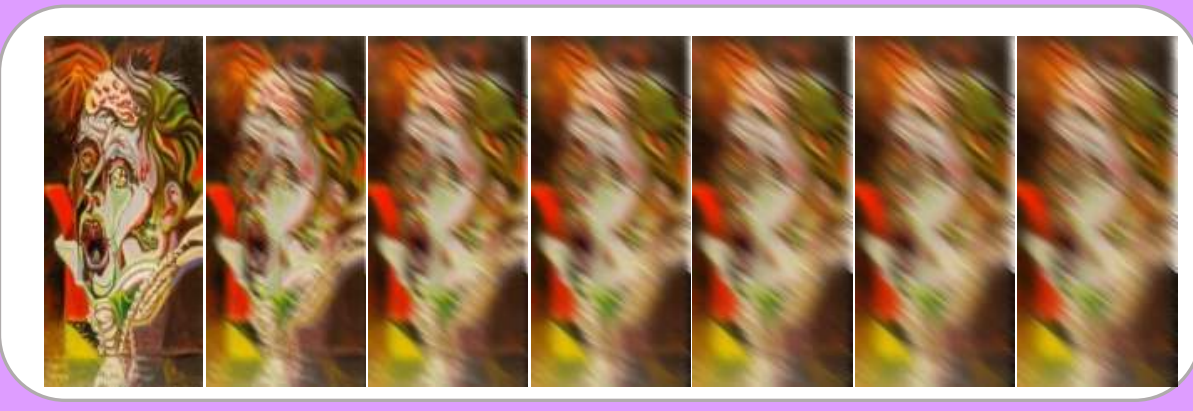

Woman dealing with mental disorder - without an aggression background:

\begin{tabular}{|r|l|l|}
\hline & Stimulus I & Stimulus II \\
\hline $1(17 \mathrm{~ms})$ & It was too fast, I could not see & Sun vase \\
\hline $2(17 \mathrm{~ms})$ & Clouds & I have nothing to say \\
\hline $3(33 \mathrm{~ms})$ & People dancing & Spinning bunny \\
\hline $4(33 \mathrm{~ms})$ & Courting $/$ wooing & I have nothing to say \\
\hline $5(50 \mathrm{~ms})$ & It present each picture twice & Small forest \\
\hline $6(50 \mathrm{~ms})$ & Process & Sun dazed \\
\hline $7(67 \mathrm{~ms})$ & Hollywood salon & Man spring \\
\hline $8(67 \mathrm{~ms})$ & Reach out your hand and touch her & The dragon \\
\hline $9(83 \mathrm{~ms})$ & People like mountains & The hat that my mother knitted for me \\
\hline $10(83 \mathrm{~ms})$ & Is there a doctor in the audience? & Man retreat \\
\hline $11(117 \mathrm{~ms})$ & Bloodshed & Chamsa (lucky talisman - shaped like a hand) \\
\hline $12(117 \mathrm{~ms})$ & Hand holding hand & Society \\
\hline $13(167 \mathrm{~ms})$ & Turned over & Scared clown \\
\hline $14(167 \mathrm{~ms})$ & Resuscitation & $\begin{array}{l}\text { The monster from Kiryat Ha-Yovel (a famous } \\
\text { sculptor in Jerusalem-lsrael) }\end{array}$ \\
\hline
\end{tabular}

